CASE REPORT

\title{
Acute Achilles Tendon Rupture Associated with Medial Malleolar Fracture: Is it Still a Rare Injury? Case Report and Review of the Literature
}

\author{
Fontecilla Nicolás ${ }^{1 *}$, Hube Maximiliano ${ }^{2}$, Bastias Gonzalo ${ }^{3}$, Fuentes Patricio ${ }^{1}$ and Arancibia Mauricio ${ }^{1}$ \\ ${ }^{1}$ Department of Trauma \& Orthopaedic Surgery, Clínica Indisa, Santiago, Chile \\ ${ }^{2}$ Department of Trauma \& Orthopaedic Surgery, $U$ de Chile University Hospital, Chile \\ ${ }^{3}$ Department of Trauma \& Orthopaedic Surgery, Clínica Las Condes, Santiago, Chile

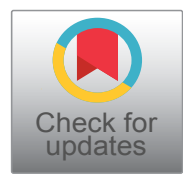

*Corresponding author: Nicolas Fontecilla, Department of Trauma \& Orthopaedic Surgery, Clínica Indisa, Santiago, Chile

\section{Introduction}

Isolated Medial malleolar fractures and Achilles tendon (AT) ruptures are relatively frequent [1]. To our knowledge, there have only been 8 cases of association of these 2 injuries published in literature [2-9]. Most of these reports were published in the last twenty years and may be the result of increased high energy trauma injuries in this period of time [10-11].

\section{Case Report}

A 57-year-old male with unremarkable previous medical history, presented to the emergency department after a motorcycle accident. He described having suffered a violent ankle dorsiflexion with external rotation as the mechanism of injury resulting with pain and functional impairment localized in the left calf and ankle. He was unable to bear weight after injury. Clinically, he had a palpable defect at the midpoint of the Achilles tendon and a positive Thompson test. In addition, the patient complained of acute swelling and tenderness located in the medial malleolus. An Achilles tendon rupture was confirmed with ultrasound imaging four centimeters proximal to its insertion in the calcaneal tuberosity and no findings were informed on plain $\mathrm{x}$-rays. The patient was referred to our practice with a temporary short leg plantar flexion cast.

The patient's x-rays were reviewed, and a questionable radiolucent line was seen in the medial malleolus consistent with a fracture that had not been initially diagnosed (Figure 1). Ankle Computed tomography (CT) was performed, confirming the diagnosis (Figure 2).

Five days following to the accident, percutaneous

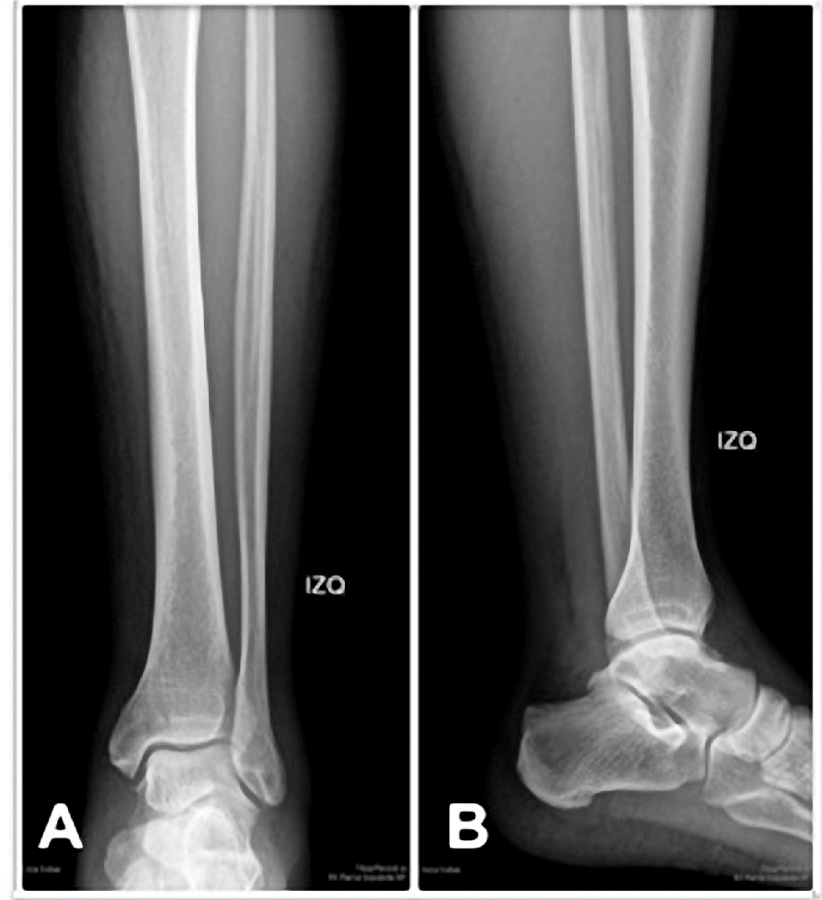

Figure 1: Ankle radiograph at presentation (A) anteroposterior view; $(B)$ lateral view, Radiolucent line is seen in the medial malleolus.

Citation: Fontecilla N, Hube M, Bastías G, Fuentes P, Arancibia M (2018) Acute Achilles Tendon Rupture Associated with Medial Malleolar Fracture: Is it Still a Rare Injury? Case Report and Review of the Literature. Int J Foot Ankle 2:017.

Accepted: November 03, 2018; Published: November 05, 2018

Copyright: (C) 2018 Fontecilla N, et al. This is an open-access article distributed under the terms of the Creative Commons Attribution License, which permits unrestricted use, distribution, and reproduction in any medium, provided the original author and source are credited. 


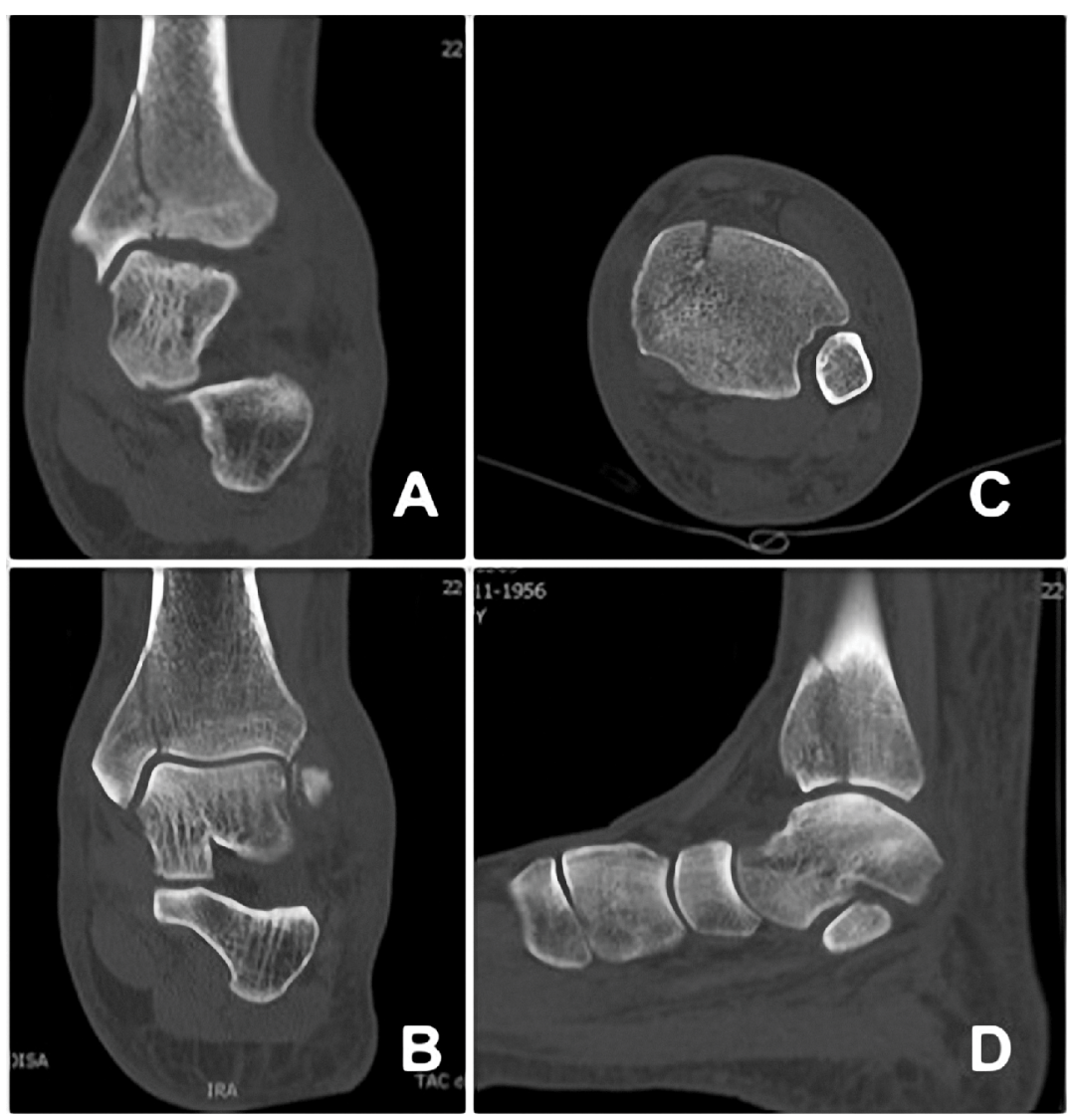

Figure 2: Ankle CT-scan at presentation (A-D), Confirming the diagnosis.
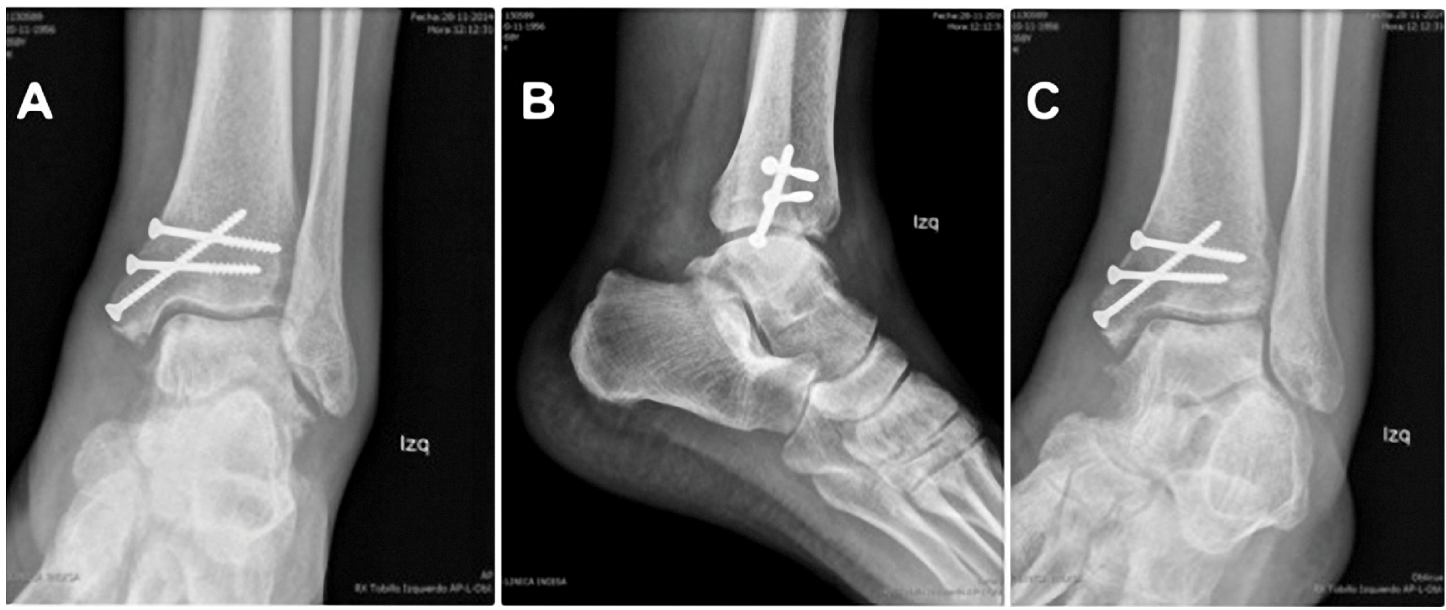

Figure 3: Ankle radiograph after surgery $(A-C)$.

Achilles repair and open reduction and internal fixation of the medial malleolus were performed under spinal anesthesia initially in supine position. A tourniquet was used during the entire surgery. Standard medial approach and blunt dissection were performed, identifying the fracture site at the anteromedial aspect of the tibial malleolus. The fracture was anatomically reduced and fixated with 3 cancellous screws (Figure 3). The medial approach was closed, and the patient was turned to the prone position, a medial longitudinal incision was made $2 \mathrm{~cm}$ proximal to the Achilles tendon Gap and the tendon was repaired with 2 fiber wire sutures using the percutaneous technique described by Amlang, et al. [12].

The ankle was maintained in a walking boot with mild equinus position to protect the repaired Achilles tendon. Sutures were removed 21 days after surgery and progressively passive dorsiflexion was allowed until a neutral position was achieved at 5 weeks. Isometric exercises with restriction of active dorsiflexion, and progressive weight loading were started on week 6 postoperatively. Follow up x-rays at 6 weeks showed successful consolidation of the medial malleolus. The removable immobilizing splint was discontinued on week 7 after surgery and full weight bearing was allowed.

At 12 months follow-up, the patient is fully recovered without any limitation in daily living activities. Functional scores showed an American Orthopedic Foot and Ankle Society (AOFAS) Ankle Hindfoot Scale [13] of 91, and The 
Achilles Tendon Total Rupture Score (ATRS) [14] of 100.

\section{Discussion}

To our knowledge, only eight single case reports of ankle fracture combined with Achilles tendon rupture have been published. Each patient sustained a complete rupture of the Achilles tendon in association with an isolated, closed, medial malleolar fracture which were either oblique or vertical. Most authors have proposed that a forced dorsiflexion of the ankle due to a sudden, high-energy impact on the plantar forefoot with a concomitant, strong contraction of the gastrocnemius muscle is the mechanism of injury.

As authors, we find it important to state that Achilles tendon rupture is usually caused by an indirect mechanism, with fast contraction of the Gastrocnemius, as when initiating a race. When finding this injury in a high energy context there must be a high degree of suspicion of associated lesions, such as medial malleolus fracture. On the other hand, when assessing ankle injuries associated to sudden dorsiflexion, an Achilles tendon rupture should be ruled out.

Physical findings included in previous reports are pain, swelling around the AT and a palpable defect around the midpoint of the tendon. Missed or delayed diagnosis of any of these injuries can lead to significant patient morbidity. Ankle swelling, tendon sheath hematoma and motor contribution by the long flexor tendons of the foot can make a clinical diagnosis of AT rupture difficult.

In at least four of the previously reported cases, either the fracture or the tendon rupture was not initially diagnosed $[3,4,6,9]$. Three cases presented a missed Achilles tendon rupture, and only one of the patients had a non-diagnosed medial malleolus fracture. We believe that the key for achieving a good functional outcome is an initial diagnosis of both injuries. Therefore, a high level of suspicion is critical.

Assal, et al. [6], proposed that all supination-adduction fractures (Danis-Weber A) should have a thorough Achilles tendon examination and, on the other hand, all Achilles tendon injuries should have routine $x$-rays in order to detect possible medial malleolar fractures. We partially agree with this routine algorithm. The most crucial tool for clinicians is a high index of suspicion. This is especially important in patients with a known AT rupture that present with periarticular edema and malleolus tenderness that is "greater than usual". We believe $\mathrm{x}$-rays are peremptory in this group of patients.

In our patient, fortunately, both lesions were diagnosed from the start.

\section{Conclusion}

This case report emphasizes the importance of having a very high index of suspicion and a thorough clinical examination to reduce the incidence of missed lesions.
Radiographic examination of the ankle is a good when physical examination is inconclusive.

We anticipate an increased number of cases in the next years.

\section{References}

1. Shibuya N, Davis ML, Jupiter DC (2014) Epidemiology of foot and ankle fractures in the United States: An analysis of the National Trauma Data Bank (2007 to 2011). J Foot Ankle Surg 53: 606-608.

2. Martin JW, Thompson GH (1986) Achilles tendon rupture. Occurrence with a closed ankle fracture. Clin Orthop Relat Res 216-218.

3. Barron JL, Yocum LA (1993) Unrecognized achilles tendon rupture associated with ipsilateral medial malleolar fracture. Am J Sports Med 21: 629-631.

4. Pieper HG, Radas CB, Quack G, Krahl H (1998) Mediomalleolar fracture combined with Achilles tendon rupture--a rare simultaneous injury of the ankle. Int J Sports Med 19: 68-70.

5. Lubin JW, Miller RA, Robinson BJ, Blevins FT (2000) Achilles tendon rupture associated with ankle fracture. Am J Orthop (Belle Mead NJ) 29: 707-708.

6. Assal M, Stern R, Peter R (2002) Fracture of the ankle associated with rupture of the Achilles tendon: Case report and review of the literature. J Orthop Trauma 16: 358-361.

7. Maffulli N, Richards PJ (2006) Subcutaneous rupture of the Achilles tendon and ipsilateral fracture of the medial malleolus. BMC Musculoskelet Disord 7: 59.

8. Nakajima K, Taketomi S, Inui H, Nakamura K, Sanada T, et al. (2016) Missed medial malleolar fracture associated with Achilles tendon rupture: A case report and literature review. J Foot Ankle Surg 55: 169-172.

9. Garneti N, Muralikuttan K, Shenolikar A (2005) Ankle fracture associated with an Achilles tendon rupture: A rare injury. Foot Ankle Surg 11: 219-222.

10. De Boer AS, Schepers T, Panneman MJ, Van Beeck EF, Van Lieshout EM (2014) Health care consumption and costs due to foot and ankle injuries in the Netherlands, 1986-2010. BMC Musculoskelet Disord 15: 128.

11. Richter M, Thermann H, Wippermann B, Otte D, Schratt $\mathrm{HE}$, et al. (2001) Foot fractures in restrained front seat car occupants: A long-term study over twenty-three years. J Orthop Trauma 15: 287-293.

12. Amlang MH, Christiani P, Heinz P, Zwipp H (2006) The percutaneous suture of the Achilles tendon with the Dresden instrument. Oper Orthop Traumatol 18: 287-299.

13. Kitaoka HB, Alexander IJ, Adelaar RS, Nunley JA, Myerson MS, et al. (1994) Clinical rating systems for the ankle-hindfoot, midfoot, hallux, and lesser toes. Foot Ankle Int 15: 349-353.

14. Nilsson Helander K, Thomee R, Silbernagel KG, Thomeé P, Faxén E, et al. (2007) The Achilles tendon Total Rupture Score (ATRS): Development and validation. Am J Sports Med 35: 421-426. 